\title{
Cellular Fatty Acid Composition as a Chemotaxonomic Marker for the Differentiation of Phenospecies and Hybridization Groups in the Genus Aeromonas
}

\author{
GEERT HUYS, ${ }^{*}$ MARC VANCANNEYT, ${ }^{1}$ RENATA COOPMAN, ${ }^{1}$ PAUL JANSSEN, ${ }^{1}$ \\ ENEVOLD FALSEN ${ }^{2}$ MARTIN ALTWEGG, ${ }^{3}$ AND KAREL KERSTERS ${ }^{1}$ \\ Laboratorium voor Microbiologie, Universiteit Gent, B-9000 Ghent, Belgium ${ }^{1}$; Department of Clinical \\ Bacteriology, University of Göteborg, S-413 46 Göteborg, Sweden'; and Institut für Medizinische \\ Mikrobiologie der Universität Zürich, CH-8028 Zürich, Switzerland ${ }^{3}$
}

\begin{abstract}
Ninety genotypically characterized Aeromonas strains, including members of all 14 currently established genospecies, were studied by performing gas-liquid chromatographic analysis of their cellular fatty acid methyl esters (FAMEs). A total of $\mathbf{4 4}$ fatty acids and two alcohols were found in members of the genus Aeromonas. All 90 strains contained 12:0, 13:0 iso, 14:0, 15:0 iso $30 H, 16: 0,16: 1 \omega 7 c, 17: 0$ iso, iso 17:1 $\omega 9 c$, summed feature 3 (16:1 iso I and/or 14:0 30H), and summed feature $7(18: 1 \omega 7 c, 18: 1 \omega 9 t$, and/or 18:1 $\omega 12 t)$, whereas all but one strain (99\%) also contained 15:0 iso. Although the FAME profiles were very similar, minor quantitative variations could be used to differentiate phenospecies and/or hybridization groups. A cluster analysis of the mean data revealed five FAME clusters, which were compared with phenotypic and genotypic groups identified in the genus Aeromonas. Hybridization groups that constituted the Aeromonas hydrophila complex, the Aeromonas caviae complex, and the Aeromonas sobria complex were basically grouped into distinct FAME clusters. The taxonomic positions of hybridization groups 7 and 11 in these clusters, however, remained unclear. All of our results were highly reproducible. A new database of Aeromonas FAME fingerprints was generated, and this database can be used for rapid identification of unknown aeromonads. Using a large set of well-characterized aeromonads, we demonstrated for the first time that gas-liquid chromatographic FAME analysis can be used to differentiate the majority of the phenospecies and/or hybridization groups in the genus Aeromonas.
\end{abstract}

Since Popoff and coworkers (26) placed 55 Aeromonas strains into DNA hybridization groups (HGs), the taxonomy of this genus has depended on a complex mixture of phenotypic and genotypic data. For this reason, biochemically distinct species are referred to as phenospecies, whereas distinct DNA HGs are usually called genospecies or genomic species. The four-species concept described in Bergey's Manual of Systematic Bacteriology (25), which was based on phenotypic characteristics, recognizes the following four groups or complexes in the genus Aeromonas: Aeromonas hydrophila (HGs 1, 2, and 3), Aeromonas caviae (HGs 4, 5A, 5B, and 6), Aeromonas sobria (HGs 7, 8, and 9), and Aeromonas salmonicida (HG 3). These groups are treated as if they are members of one (pheno)species, although each consists of one or more HGs. In contrast, strains belonging to the recently described taxa Aeromonas veronii biogroup veronii (HG 10), Aeromonas schubertii (HG 12), and Aeromonas trota (HG 13) seem to be genotypically homogeneous; in these cases each phenospecies corresponds to one HG. So far, the genus Aeromonas contains at least 11 phenospecies and at least 14 HGs $(17,37)$. Several of the genospecies are difficult to separate biochemically or have not been named yet because of a lack of phenotypic characteristics that correlate well with DNA-DNA homology data (4). Along with the ever-changing taxonomic situation of the genus Aeromonas, the question of whether aeromonads should be considered human opportunistic pathogens has been controversial. In fact, aeromonads have been associated with a broad range of infections in cold- and warm-blooded animals, but until now there has been little or no evidence that putative virulence

\footnotetext{
* Corresponding author. Mailing address: Laboratorium voor Microbiologie, Universiteit Gent, K.-L. Ledeganckstr. 35, B-9000 Ghent, Belgium. Phone: 32.9 2645121. Fax: 32.92645346.
}

factors of aeromonads (e.g., hemolysin) can be unequivocally linked to the disease process itself (17).

For the past 10 years there has been a strong need for the development and application of new typing methods to address the current taxonomic and pathogenic problems in the genus Aeromonas. Until recently, it seemed that most chemotaxonomic typing methods could be used only for epidemiological purposes. Methods such as serotyping (13), sodium dodecyl sulfate-polyacrylamide gel electrophoresis of whole-cell proteins (32), and phage typing (2) are very useful for differentiating individual Aeromonas strains but are too sensitive to have any taxonomic value. Data obtained by biotyping $(9,19)$ and multilocus enzyme electrophoresis $(3,24,33)$ correlated well with DNA-DNA hybridization data; however, these techniques are time consuming and require too many reagents to be of practical use in routine analyses.

Gas-liquid chromatographic analysis of fatty acid methyl esters (FAMEs) does not have the disadvantages described above and has been used extensively for routine microbial identification and classification $(18,31,34-36,38)$. Only a few major studies of the cellular fatty acid compositions of Aeromonas species have been published previously. Originally, fatty acid analysis seemed to be useful only for separating clinical aeromonads as a group from nonclinical aeromonads $(5,13)$. Later, Canonica and Pisano (6) and Hansen and coworkers (12) described minor differences in the FAME profiles of clinical strains as well as nonclinical strains of $A$. hydrophila, $A$. caviae, and $A$. sobria. The cellular fatty acid compositions of the more recently described Aeromonas species $(7,8,14,15)$, however, have received very little attention (12). In addition, no previously described FAME study included Aeromonas strains belonging to particular HGs or paid attention to the striking taxonomic differences between the phenospecies and genospecies identified in the genus Aeromonas. 
To our knowledge, this paper is the first report that describes the fatty acid profiles of genotypically characterized Aeromonas strains which represent all currently established HGs in the genus Aeromonas. Two recently described species, Aeromonas ichthiosmia (29) and Aeromonas enteropelogenes (28), were not included in this study because on the basis of phylogenetic evidence it appears that these organisms are not new species but rather are identical to $A$. veronii biogroup veronii and $A$. trota, respectively (10). Strains of the nonmotile psychrophilic species $A$. salmonicida grow weakly when they are cultivated at $28^{\circ} \mathrm{C}$ and are therefore not discussed in this paper. Our aims were (i) to determine whether there are qualitative and/or quantitative differences in the mean FAME profiles of the different HGs, (ii) to correlate our findings with previously published phenotypic, genotypic, and FAME data, and (iii) to create a database of Aeromonas FAME fingerprints which can be used for rapid identification of unknown aeromonads.

\section{MATERIALS AND METHODS}

Strains. All of the bacterial cultures which we used were obtained from the Culture Collection of the Laboratorium voor Microbiologie, Universiteit Gent, Ghent, Belgium, the Culture Collection of the University of Göteborg, Göteborg, Sweden, and the Institute of Medical Microbiology, University of Zürich, Zurich, Switzerland. Details concerning the strains are shown in Table 1 . The strains used for fatty acid analysis were cultured aerobically on Trypticase soy agar containing $3 \%$ (wt/vol) Trypticase soy broth (BBL) and $1.5 \%$ (wt/vol) Bacto Agar (Difco) at $28^{\circ} \mathrm{C}$ for 24 and/or $48 \mathrm{~h}$.

FAME analysis. FAMEs were prepared and extracted by using the standardized protocol of the Microbial Identification System (MIDI; Microbial ID, Inc., Newark, Del.). The extracts were analyzed with a Hewlett-Packard model HP5890A gas chromatograph equipped with a flame ionization detector, an automatic sampler, an integrator, and a computer, as described previously (23). Identification of the FAME fingerprints, generation and validation of the database, and unweighted arithmetic average cluster analysis were performed by using the MIDI software package (version 3.7).

\section{RESULTS AND DISCUSSION}

Reproducibility. Bacterial fatty acid composition varies with the culture medium, the incubation temperature, and the physiological age of the cell population. However, several investigators have demonstrated that highly reproducible fatty acid profiles can be obtained if all of these experimental parameters are standardized (23). We recultivated five strains three or four times and analyzed their FAME extracts under the highly standardized conditions described in the Microbial Identification System protocol. In general, the data for the most common fatty acids varied less than $3 \%$, thus indicating that the procedure had good reproducibility.

Influence of the physiological cell age. Five strains belonging to HGs 1,2 , and 3 (phenotypically $A$. hydrophila), HGs 4, 5A, and $5 \mathrm{~B}$ (phenotypically $A$. caviae or Aeromonas media), or HG 8 (phenotypically $A$. veronii biogroup sobria) were incubated on Trypticase soy agar at $28^{\circ} \mathrm{C}$ for 24 and $48 \mathrm{~h}$. More reproducible FAME patterns were obtained after incubation for $48 \mathrm{~h}$. At the genospecies level, more characteristic differences that could be used for differentiation of HGs 4, 5A, and $5 \mathrm{~B}$ were obtained after $48 \mathrm{~h}$ of incubation. Only slightly better separation of HGs 1, 2, and 3 was obtained with the 24-h data (data not shown). To delineate the groups at the phenospecies level, the FAME profiles obtained after $48 \mathrm{~h}$ clearly had more differentiating characteristics than the FAME profiles obtained after $24 \mathrm{~h}$. These results indicate that better taxonomic resolution would be obtained if all subsequent analyses are performed after $48 \mathrm{~h}$ of incubation. This is in contrast to the results of previous fatty acid analyses of aeromonads $(6,12$, 13 ), in which cells were harvested after $24 \mathrm{~h}$. It is interesting that, in close agreement with our results, more characteristic differences between taxa were obtained with the FAME profiles of Xanthomonas strains after $48 \mathrm{~h}$ of growth $(30,38)$.

Fatty acids in Aeromonas strains. A total of 44 fatty acids and two alcohols were detected in a gas-liquid chromatographic analysis of 90 genotypically characterized Aeromonas strains. Seventeen FAMEs were present in less than $5 \%$ of the strains tested or were present at levels of less than $0.1 \%$; these FAMEs were not included in our analysis. The frequencies and mean percentages of the other 29 FAMEs are shown in Table 2.

All 90 strains contained 12:0, 13:0 iso, 14:0, 15:0 iso $3 \mathrm{OH}$, $16: 0,16: 1 \omega 7 c, 17: 0$ iso, iso $17: 1 \omega 9 c$, summed feature $3(16: 1$ iso I and/or 14:0 3OH), and summed feature $7(18: 1 \omega 7 c, 18: 1$ $\omega 9 t$, and/or 18:1 $\omega 12 t$ ), and all but one strain (LMG 13453, belonging to HG 3) contained 15:0 iso. Clearly, these 11 features should be considered the most characteristic fatty acids of the genus Aeromonas. Together with two other fatty acids $(15: 0$ and 17:1 $\omega 8 c)$, which appeared in $85(94 \%)$ of the strains, the 11 features mentioned above accounted for almost $93 \%$ of the total cellular fatty acid composition of the genus Aeromonas. Consequently, differentiation among phenospecies and/or HGs depended almost entirely on quantitative differences among the FAME profiles.

Unsaturated fatty acid $16: 1 \omega 7 c$ was the predominant fatty acid (mean level, 29.9\%), whereas the saturated fatty acid 16:0 and the unsaturated fatty acid 18:1 (summed feature 7) were the second and third most common fatty acids (relative percentages, 14.4 and $9.9 \%$, respectively). These three major components accounted for almost $55 \%$ of the total cellular fatty acids. Hansen and coworkers (12) reported that these components accounted for up to $60 \%$ of the total fatty acids of 39 Aeromonas strains which they studied, although the experimental conditions used by these authors (growth medium, incubation temperature, and incubation time) were totally different from the conditions which we used. This finding indicates that standardization of these parameters probably would have little or no influence on the relative amounts of the major fatty acids.

Lambert and coworkers (21) found that members of the Vibrionaceae (the genera Vibrio, Aeromonas, Photobacterium, and Plesiomonas) could be differentiated from Escherichia coli (Enterobacteriaceae) because the concentration of 16:1 $\omega 7 \mathrm{c}$ in the members of the Vibrionaceae was at least 1.5 times greater than the concentration of $16: 0$, while in $E$. coli this ratio was less than 1.0. Using the mean values for the fatty acid contents, we found a 16:1 $\omega 7 \mathrm{c} / 16: 0$ ratio of 2.1 for the genus Aeromonas, which may indicate that there is a close relationship between the genus Aeromonas and the Vibrionaceae. In addition, all 90 Aeromonas strains lacked the cyclopropane fatty acids usually found in most genera of the Enterobacteriaceae. In the study of Lambert et al. (21), A. hydrophila and $A$. salmonicida were differentiated from all other members of the Vibrionaceae because they did not contain 13:1 iso and contained only trace amounts of 12:0 $3 \mathrm{OH}$. This may support the view that establishment of a separate family, the Aeromonadaceae, would be appropriate (11). The results of a FAME analysis of 12 clinical Aeromonas strains performed by Canonica and Pisano (5) demonstrated that the hydroxy fatty acid profiles obtained 
TABLE 1. Strains used

\begin{tabular}{|c|c|c|c|c|c|}
\hline Phenospecies & $\mathrm{HG}^{a}$ & Cluster $^{b}$ & Strain $^{c, d}$ & $\begin{array}{l}\text { Designation as received and/ } \\
\text { or other designation }{ }^{c, d}\end{array}$ & Source of isolation \\
\hline \multirow[t]{23}{*}{ A. hydrophila } & \multirow[t]{10}{*}{1} & \multirow[t]{10}{*}{$\mathrm{E}$} & LMG $2844^{\mathrm{T}}$ & ATCC $7966^{\mathrm{T}}$, A $306^{\mathrm{T}}$, CCUG $14551^{\mathrm{T}}$ & Milk with fishy odor \\
\hline & & & LMG 13439 & A 17 & Unknown \\
\hline & & & LMG 13440 & A 19 & Unknown \\
\hline & & & LMG 13441 & A 34 & Feces \\
\hline & & & LMG 13442 & A 52 & Feces \\
\hline & & & LMG 13443 & A 229 & Feces \\
\hline & & & LMG 13657 & A 145 & Feces \\
\hline & & & LMG 13658 & A 162 & Feces \\
\hline & & & LMG 13659 & A 167 & Feces \\
\hline & & & LMG 13660 & A 188 & Contaminated Bactec vial \\
\hline & \multirow[t]{6}{*}{2} & \multirow[t]{6}{*}{$\mathrm{E}$} & LMG $13444^{\mathrm{R}}$ & A $307^{\mathrm{R}}$ & Diseased fish \\
\hline & & & LMG 13445 & A 2 & Human \\
\hline & & & LMG 13446 & A 13 & Environment \\
\hline & & & LMG 13447 & A 39 & Water \\
\hline & & & LMG 13448 & A 169 & Feces \\
\hline & & & LMG 13662 & A 295 & Feces \\
\hline & \multirow[t]{7}{*}{3} & \multirow[t]{7}{*}{$\mathrm{E}$} & LMG $13449^{\mathrm{R}}$ & A $99^{R}$ & Feces \\
\hline & & & LMG 13450 & A 63 & Feces \\
\hline & & & LMG 13451 & A 308 & Freshwater \\
\hline & & & LMG 13452 & A 7 & Environment \\
\hline & & & LMG 13453 & A 8 & Environment \\
\hline & & & LMG 13674 & A 14 & Environment \\
\hline & & & LMG 13675 & A 15 & Environment \\
\hline \multirow[t]{24}{*}{ A. caviae } & \multirow[t]{10}{*}{4} & \multirow[t]{10}{*}{ B } & LMG $3775^{\mathrm{T}}$ & ATCC $15468^{\mathrm{T}}$, A $309^{\mathrm{T}}$, CCUG $25939^{\mathrm{T}}$ & Epizootic, guinea pig \\
\hline & & & LMG 13454 & A 1 & Human \\
\hline & & & LMG 13455 & A 30 & Blood culture \\
\hline & & & LMG 13456 & A 41 & Feces \\
\hline & & & LMG 13457 & A 102 & Feces \\
\hline & & & LMG 13658 & A 234 & Feces \\
\hline & & & LMG 13676 & A 12 & Environment \\
\hline & & & LMG 13677 & A 20 & Feces \\
\hline & & & LMG 13678 & A 26 & Blood culture \\
\hline & & & LMG 13680 & A 61 & Feces \\
\hline & \multirow[t]{9}{*}{$5 \mathrm{~A}$} & \multirow[t]{9}{*}{$\mathrm{C}$} & LMG $13459^{\mathrm{R}}$ & A $310^{R}$ & Fish \\
\hline & & & LMG 13460 & A 6 & Environment \\
\hline & & & LMG 13461 & A 75 & Feces \\
\hline & & & LMG 13462 & A 93 & Feces \\
\hline & & & LMG 13463 & A 196 & Feces \\
\hline & & & LMG 13681 & A 163 & Feces \\
\hline & & & LMG 13682 & A 170 & Feces \\
\hline & & & LMG 13683 & A 208 & Feces \\
\hline & & & LMG 13684 & A 225 & Feces \\
\hline & $5 \mathrm{~B}$ & $\mathrm{C}$ & LMG 13464 & A 904 & Fish \\
\hline & & & LMG 13465 & A 117 & Feces \\
\hline & & & LMG 13466 & A 213 & Feces \\
\hline & & & LMG 13467 & A 242 & Feces \\
\hline & & & LMG 13468 & A 284 & Feces \\
\hline A. media & $5 B$ & $\mathrm{C}$ & LMG $9073^{\mathrm{T}}$ & ATCC $33907^{\mathrm{T}}$, A $912^{\mathrm{T}}$ & Water \\
\hline A. eucrenophila & 6 & $\mathrm{C}$ & LMG $3774^{\mathrm{T}}$ & NCMB $74^{\mathrm{T}}$, A $311^{\mathrm{T}}$, CCUG $30340^{\mathrm{T}}$ & Freshwater fish \\
\hline & & & LMG 13057 & CCUG 30341, A 914 & Unknown \\
\hline & & & LMG 13058 & CCUG 30342, A 1650 & Carp \\
\hline & & & LMG 13060 & CCUG 30344, A 1652 & Water \\
\hline & & & LMG 13061 & CCUG 30345 , A 1653 & Water \\
\hline & & & LMG 13687 & CCUG 30343 , A 1651 & Water \\
\hline & & & LMG 13691 & CCUG 30347, A 1655 & Groundwater \\
\hline A. sobria & 7 & $\mathrm{E}$ & LMG $3783^{\mathrm{T}}$ & CIP $74.33^{\mathrm{T}}$, A $312^{\mathrm{T}}$, CCUG $14830^{\mathrm{T}}$ & Fish \\
\hline & & & LMG 13469 & A 915 & Fish \\
\hline A. veronii biogroup sobria & 8 & A & LMG 13067 & CCUG 30356, A 10 & Environment \\
\hline & & & LMG 13068 & CCUG 30357, A 64 & Feces \\
\hline & & & LMG 13069 & CCUG 30358, A 66 & Feces \\
\hline & & & LMG 13070 & CCUG 30359 , A 68 & Feces \\
\hline & & & LMG 13071 & CCUG 30360, A 132 & Feces \\
\hline & & & LMG 13072 & CCUG 30361, A 151 & Feces \\
\hline & & & LMG 13073 & CCUG 30362, A 155 & Feces \\
\hline & & & LMG 13074 & CCUG 30363 , A 916 & Feces \\
\hline & & & LMG 13693 & A 11 & Environment \\
\hline & & & LMG 13694 & A 27 & Unknown \\
\hline
\end{tabular}


TABLE 1-Continued

\begin{tabular}{|c|c|c|c|c|c|}
\hline Phenospecies & $\mathrm{HG}^{a}$ & Cluster $^{b}$ & Strain ${ }^{c, d}$ & $\begin{array}{l}\text { Designation as received and/ } \\
\text { or other designation }^{c, d}\end{array}$ & Source of isolation \\
\hline & & & LMG 13695 & A 28 & Feces \\
\hline & & & LMG 13700 & A 168 & Feces \\
\hline \multirow[t]{7}{*}{ A. jandaei } & 9. & A & LMG $12221^{\mathrm{T}}$ & ATCC $49568^{\mathrm{T}}$, A $1642^{\mathrm{T}}$, CCUG $30353^{\mathrm{T}}$ & Feces \\
\hline & & & LMG 13064 & CCUG 30348, A 179 & Feces \\
\hline & & & LMG 13065 & CCUG 30350, A 919 & Feces \\
\hline & & & LMG 13066 & CCUG 30351, A 950 & Unknown \\
\hline & & & LMG 13077 & CCUG 30352, A 1641, ATCC 49570 & Wound below left eye \\
\hline & & & LMG 13078 & CCUG 30354 , A 1643, ATCC 49572 & Prawn, Hawaii \\
\hline & & & LMG 13079 & CCUG 30355, A 1644, ATCC 49571 & Leg wound, diver \\
\hline \multirow[t]{4}{*}{ A. veronii biogroup veronii } & 10 & $\mathrm{D}$ & LMG $9075^{\mathrm{T}}$ & ATCC $35624^{\mathrm{T}}$, A $901^{\mathrm{T}}$ & Near-drowning victim \\
\hline & & & LMG 13470 & A 925 & Kidney of tarbot \\
\hline & & & LMG 13471 & A 923 & Kidney of brook trout \\
\hline & & & LMG 13472 & A 924 & Kidney of rainbow trout \\
\hline \multirow[t]{2}{*}{ A. veronii } & 11 & $\mathrm{C}$ & LMG 13075 & CCUG 30364, A 902, ATCC 35941 & Ankle fracture \\
\hline & & & LMG 13076 & CCUG 30365 , A 926 & Water, Mohawk River \\
\hline \multirow[t]{4}{*}{ A. schubertii } & 12 & A & LMG $9074^{\mathrm{T}}$ & ATCC $43700^{\mathrm{T}}$, A $903^{\mathrm{T}}$, CCUG $27820^{\mathrm{T}}$ & Abscess on forehead \\
\hline & & & LMG 12655 & CCUG 25582 & Human leg wound \\
\hline & & & LMG 12668 & CCUG 25583 & Human leg wound \\
\hline & & & LMG 13473 & A 922, ATCC 43701 & Human skin \\
\hline \multirow[t]{4}{*}{ A. trota } & 13 & A & LMG $12223^{\mathrm{T}}$ & ATCC $49657^{\mathrm{T}}$, A $1646^{\mathrm{T}}$, CCUG $30367^{\mathrm{T}}$ & Stool, India \\
\hline & & & LMG 13080 & CCUG 30366, A 1645, ATCC 49659 & Appendix \\
\hline & & & LMG 13081 & CCUG 30368, A 1647, ATCC 49660 & Stool, Thailand \\
\hline & & & LMG 13082 & CCUG 30369, A 1648, ATCC 49658 & Stool, Bangladesh \\
\hline
\end{tabular}

${ }^{a} \mathrm{HG}$ as determined in the DNA homology study of Altwegg and coworkers (4).

${ }^{b}$ FAME cluster comprising one or more HGs as determined by cluster analysis of the mean fatty acid profiles (Fig. 1).

${ }^{c} \mathrm{~T}=$ type strain. $\mathrm{R}=$ hybridization group reference strain.

${ }^{d}$ A, Institute of Medical Microbiology, Zürich, Switzerland; ATCC, American Type Culture Collection, Rockville, Md.; CCUG, Culture Collection of the University of Göteborg, Göteborg, Sweden; CIP, Collection bactérienne de l'Institut Pasteur, Paris, France; LMG, Laboratorium voor Microbiologie Culture Collection, Ghent, Belgium; NCMB, National Collection of Marine Bacteria, Aberdeen, Scotland.

from clinical strains are, in part, qualitatively different from the profiles of isolates that have nonclinical origins; e.g., $12: 03 \mathrm{OH}$ was found only in clinical aeromonads. In our study, the fatty acid profiles of 90 strains revealed that not a single strain produces $13: 1$ iso and that 34 strains $(38 \%)$ contain $12: 030 \mathrm{H}$ in trace amounts (up to $0.6 \%$ ); 28 of these 34 strains are clinical isolates, and 6 are nonclinical isolates. In general, these findings are in agreement with the results of both previously described FAME studies $(5,13)$, although clear differentiation between strains that have clinical and nonclinical origins remains problematic.

Cluster analysis. Mean profiles were determined for all strains belonging to a particular HG. Unweighted arithmetic average clustering of the resulting 14 HG-specific profiles revealed five FAME clusters when the taxa were delineated at an Euclidian distance of 7 (Fig. 1). In general, the same clusters (clusters A through $\mathrm{E}$ ) were found when the individual fatty acid profiles of all of the strains were used. However, since the clustering method which we used was based mainly on an overall comparison of FAME profiles, no clear differentiation of genospecies was obtained within the major FAME clusters (clusters A through E). Therefore, Fig. 1 is a simplified dendrogram in which the mean fatty acid profiles of the HGs are grouped together. Table 3 shows the mean fatty acid contents and standard deviations for the 14 HGs. The significant differences in the FAME profiles at the phenospecies level as well as at the genospecies level were mainly quantitative and are discussed below.

FAME cluster A contained 27 strains belonging to HGs 8, 9, 12 , and 13 and was very well separated from the other four clusters at a Euclidian distance of 12.5. Together with the members of FAME cluster B, the members of this cluster contained the lowest relative amounts $(22.0$ to $25.8 \%)$ of $16: 1$ $\omega 7 c$ found in the genus Aeromonas. Except for A. trota (HG 13) all members of cluster A contained significant amounts of the saturated fatty acid 13:0 (0.6 to $1.3 \%)$.

FAME cluster B was delineated at a Euclidian distance of 10.5 and was defined by the mean profile of $10 \mathrm{~A}$. caviae $\mathrm{HG} 4$ strains. Together with the members of HG 12, the members of this FAME group contained the highest relative amount of the branched fatty acid 13:0 iso (3.1\%).

FAME cluster $\mathrm{C}$ comprised HGs $5 \mathrm{~A}, 5 \mathrm{~B}, 6$, and 11 , and its members were linked at a Euclidian distance of 7.7. This cluster was the only cluster whose members produced significantly fewer fatty acids (they produced 13 to 15 fatty acids) and lacked both 16:0 $\mathrm{N}$ alcohol and 16:1 $\omega 7 \mathrm{c}$ alcohol. Together with the members of HG 4, the members of all of these HGs lacked the branched fatty acid 17:0 10 Me. In addition, they produced only trace amounts (up to $0.6 \%$ ) of 15:0,16:0 iso, 17:0, and 17:1 $\omega 8 c$.

FAME cluster D was defined by the mean profile of four $A$. veronii biogroup veronii (HG 10) strains and was delineated at a Euclidean distance of 7. The dendrogram in Fig. 1 clearly indicates that this FAME group is closely related to FAME clusters $\mathrm{C}$ and $\mathrm{E}$.

FAME cluster $\mathrm{E}$ was defined by the mean FAME data for 25 strains belonging to $A$. sobria (HG 7) and $A$. hydrophila (HGs 1,2 , and 3 ) and was closely related to cluster $\mathrm{D}$, as discussed above. The members of HGs 1,2 , and 3 are characterized by the highest relative amounts $(17.3$ to $18.2 \%)$ of the saturated fatty acid 16:0 found in the genus Aeromonas.

Generation of an Aeromonas database. In a previous paper (16), we described the first results which indicated the resolving power of a new database, AER48. This database contains the mean FAME data for 70 genotypically characterized aeromonads, including members of all currently established 
TABLE 2. Major fatty acids of 90 genotypically identified strains belonging to the genus Aeromonas ${ }^{a}$

\begin{tabular}{|c|c|c|c|}
\hline \multirow{2}{*}{ Compound } & \multirow{2}{*}{$\begin{array}{l}\text { Frequency } \\
(\%)\end{array}$} & \multicolumn{2}{|c|}{$\begin{array}{c}\% \text { in Aeromonas } \\
\text { strains }\end{array}$} \\
\hline & & $\operatorname{Mean}^{b}$ & Range \\
\hline \multicolumn{4}{|l|}{ Saturated fatty acids } \\
\hline $12: 0$ & 100.0 & 7.1 & $3.1-14.6$ \\
\hline $13: 0$ & 64.4 & 0.4 & $0.0-1.6$ \\
\hline $14: 0$ & 100.0 & 2.9 & $1.1-5.6$ \\
\hline $15: 0$ & 94.4 & 1.2 & $0.0-4.5$ \\
\hline $16: 0$ & 100.0 & 14.4 & $7.4-23.2$ \\
\hline $17: 0$ & 81.1 & 0.9 & $0.0-2.8$ \\
\hline $18: 0$ & 66.7 & 0.3 & $0.0-1.2$ \\
\hline \multicolumn{4}{|l|}{ Unsaturated fatty acids ${ }^{c}$} \\
\hline $16: 1 \omega 7 c$ & 100.0 & 29.9 & $17.9-40.1$ \\
\hline $17: 1 \omega 8 c$ & 94.4 & 1.7 & $0.0-5.4$ \\
\hline $17: 1 \omega 6 c$ & 46.7 & 0.3 & $0.0-1.4$ \\
\hline \multicolumn{4}{|l|}{ Branched fatty acids } \\
\hline $13: 0$ iso & 100.0 & 1.9 & $0.4-4.4$ \\
\hline $14: 0$ iso & 18.9 & 0.1 & $0.0-1.5$ \\
\hline $15: 1$ iso $\mathrm{F}^{d}$ & 23.3 & 0.1 & $0.0-1.2$ \\
\hline $15: 0$ iso & 98.9 & 3.0 & $0.0-7.2$ \\
\hline $16: 0$ iso & 83.3 & 1.1 & $0.0-3.6$ \\
\hline iso $17: 1 \omega 9 c^{c}$ & 100.0 & 3.9 & $0.6-13.5$ \\
\hline $17: 0$ iso & 100.0 & 4.6 & $0.5-14.7$ \\
\hline 17:0 anteiso & 26.7 & 0.1 & $0.0-0.7$ \\
\hline 17:0 10 methyl & 40.0 & 0.6 & $0.0-4.4$ \\
\hline Hydroxy fatty acid $(12: 03 \mathrm{OH})$ & 37.8 & 0.1 & $0.0-0.6$ \\
\hline \multicolumn{4}{|l|}{ Branched hydroxy fatty acids } \\
\hline $14: 0$ iso $3 \mathrm{OH}$ & 50.0 & 0.3 & $0.0-1.6$ \\
\hline $15: 0$ iso $3 \mathrm{OH}$ & 100.0 & 4.3 & $0.8-10.4$ \\
\hline \multicolumn{4}{|l|}{ Unknowns ${ }^{e}$} \\
\hline Unknown 13.961 & 37.8 & 0.3 & $0.0-1.0$ \\
\hline Unknown 14.503 & 58.9 & 0.4 & $0.0-1.2$ \\
\hline \multicolumn{4}{|l|}{ Summed features $f$} \\
\hline Summed feature 2 & 32.2 & 0.4 & $0.0-1.8$ \\
\hline Summed feature 3 & 100.0 & 8.0 & $3.5-17.1$ \\
\hline Summed feature 7 & 100.0 & 9.9 & $5.7-22.3$ \\
\hline \multicolumn{4}{|l|}{ Alcohols } \\
\hline $16: 0 \mathrm{~N}$ & 34.4 & 0.4 & $0.0-3.0$ \\
\hline $16: 1 \omega 7 c$ & 48.9 & 1.4 & $0.0-10.4$ \\
\hline
\end{tabular}

${ }^{a}$ Fatty acids $11: 0$ iso, 11:0, unknown $11.541,12: 0$ iso, unknown $11.798,14: 1$ iso E, 15:0 anteiso, 15:1 $\omega 8 c, 15: 1 \omega 6 c, 15: 02 \mathrm{OH}, 15: 03 \mathrm{OH}, 18: 0$ iso, 19:0 anteiso, 19:1 $\omega 12 t, 20: 1 \omega 9 t$, summed feature 5 , and summed feature 6 were present in less than $5 \%$ of the strains tested or were present at levels of less than $0.1 \%$ (mean value). When the MIDI system was used, gas-liquid chromatography also revealed the presence of two $\mathrm{C}_{16}$ alcohols.

${ }^{b}$ Mean values were calculated by using FAME data for the 90 strains listed in Table 1, regardless of the fact that every fatty acid was not detected in all of the strains.

${ }^{c}$ The position of the double bond can be located by counting from the methyl ( $\omega)$ end of the carbon chain. A cis isomer is indicated by the suffix $c$.

${ }^{d}$ The double bond position indicated by a capital letter is unknown.

${ }^{e}$ The unknown fatty acids have no name listed in the Peak Library File of the MIDI system and therefore can be identified only by their equivalent chain lengths.

$f$ Summed features represent groups of two or three fatty acids which could not be separated by gas-liquid chromatography with the MIDI system. Summed feature 2 contained one or more of the following fatty acids: 13:0 $3 \mathrm{OH}, 15: 1$ iso $\mathrm{I}$, and/or 15:1 iso $\mathrm{H}$. Summed feature 3 contained 16:1 iso I and/or 14:0 $3 \mathrm{OH}$. Summed feature 7 contained one or more of the following isomers: 18:1 $\omega 7 c$, 18:1 $\omega 9 t$, and/or 18:1 $\omega 12 t$ (cis and trans isomers are indicated by the suffixes $c$ and $t$, respectively).

Aeromonas genospecies. Aeromonas allosaccharophila (22) and enteric group 501 (14) were not investigated because they have not been assigned to an HG yet. Using AER48, we classified $228(92 \%)$ of 249 presumptive aeromonads isolated from various drinking water supplies in the genus Aeromonas, whereas $186(82 \%)$ and $125(55 \%)$ strains were assigned to

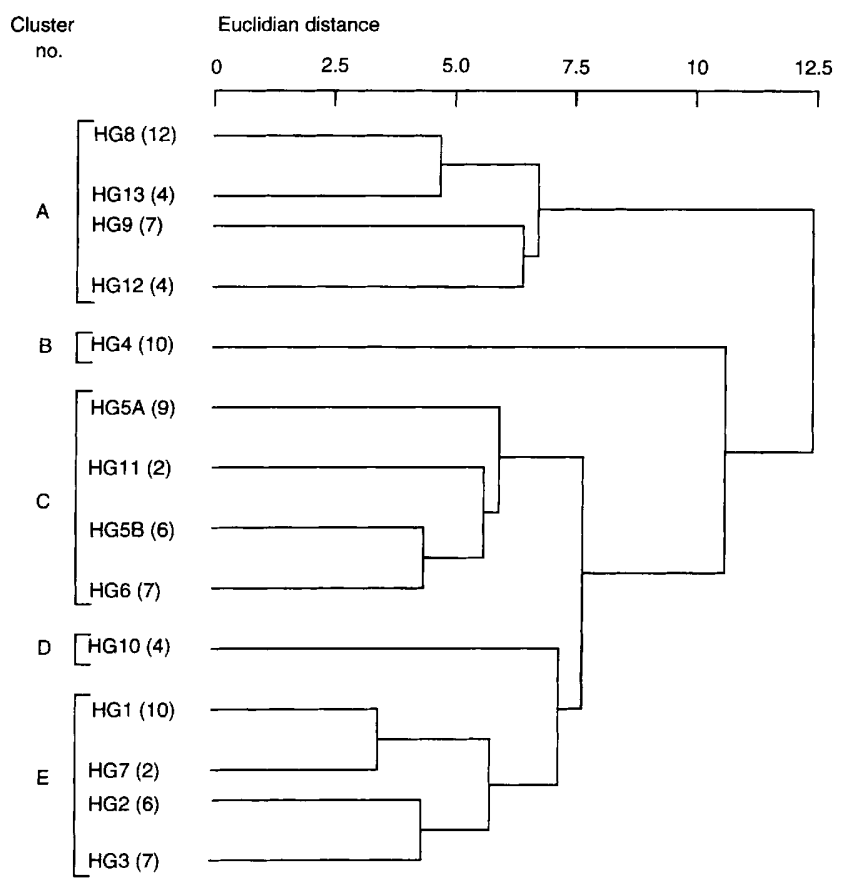

FIG. 1. Dendrogram showing the FAME clusters revealed by a numerical analysis of the mean fatty acid profiles of all $14 \mathrm{HGs}$ in the genus Aeromonas. The numbers of strains tested are indicated in parentheses.

phenospecies and HGs, respectively. These values suggest that this database has shortcomings and/or indicate that there are additional, currently undescribed phenospecies and/or HGs. However, certain HGs (HGs 7 and 11) are represented by only a small number of strains, and this may give rise to statistical variations in the cluster analysis results and in identification of unknown aeromonads. To address these problems, we recently added 20 well-characterized aeromonads to the database, which now contains the fatty acid profiles of all 90 strains mentioned in this paper (data not shown).

Comparison of FAME data with phenotypic and genotypic data. The FAME data were compared mainly with data from previous taxonomic studies which included basically all of the strains used in this investigation. Kämpfer and Altwegg (19) used 329 biochemical characteristics to differentiate 176 Aeromonas strains representing all currently established genospecies and identified 16 phena which contained two or more strains. Altwegg (1) and Altwegg et al. (4) determined the levels of DNA relatedness for 116 aeromonads by the hydroxyapatite method and included strains in the same genospecies or $\mathrm{HG}$ if the relative binding ratios were more than $70 \%$ at $60^{\circ} \mathrm{C}$ and/or more than $60 \%$ at $75^{\circ} \mathrm{C}$. Data from these two studies correlated well with each other, and moreover, our FAME clusters are basically in agreement with the majority of the phenotypic (19) and genotypic $(1,4)$ groups identified previously.

FAME cluster A contains the genospecies $A$. veronii biogroup sobria (HG 8), Aeromonas jandaei (HG 9), A. schubertii (HG 12), and $A$. trota (HG 13), all of which contain strains isolated from clinical sources $(7,8,14,20)$. According to the four-species concept (25), strains belonging to genospecies 7 , 8 , and 9 (A. sobria complex) are phenotypically highly related. The tight grouping in this complex has also been confirmed by DNA-DNA hybridizations data; levels of DNA homology 


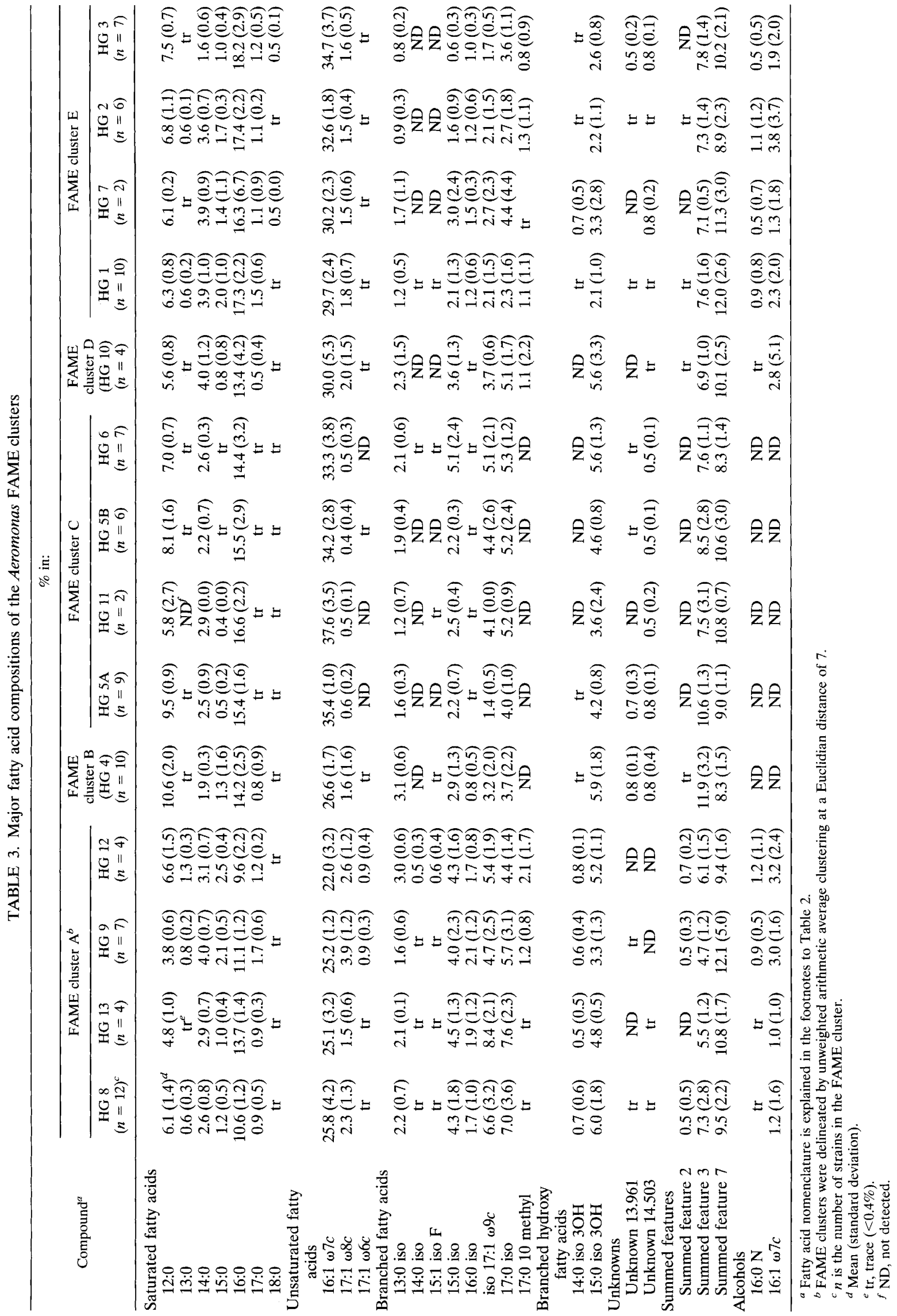


ranging from 36 to $76 \%$ at $60^{\circ} \mathrm{C}$ have been found (1). HGs 12 and 13 are phenotypically quite similar to HGs 7,8 , and 9 . In fact, Kämpfer and Altwegg (19) placed these five genospecies in a distinct phenon which is, except for the presence of $\mathrm{HG} \mathrm{7,}$ basically similar to FAME cluster A. The absence of HG 7 in the latter group and the lack of FAME relatedness between the phenotypically very similar genospecies $A$. sobria (HG 7) and $A$. veronii biogroup sobria (HG 8) are probably due to the fact that only two strains of $\mathrm{HG} 7$ were included, which, on the basis of their FAME profiles, are quite heterogeneous. This suggestion was readily confirmed by the results of a cluster analysis of the type and reference strains of all Aeromonas genospecies; in this analysis tight clustering was found between LMG 3783 and LMG 13074, the type strain and the reference strain of HGs 7 and 8, respectively (data not shown).

FAME cluster B comprises $A$. caviae $\mathrm{HG} 4$, a member of the $A$. caviae complex which also contains HGs $5 \mathrm{~A}$ (A. caviae) and 5B ( $A$. caviae and $A$. media), and the aerogenic species Aeromonas eucrenophila (HG 6) (27). The levels of DNA-DNA relatedness within this complex range from 38 to $69 \%$ at $60^{\circ} \mathrm{C}$ (1). The phenotypic and genotypic diversity in genospecies 5 indicates that this genospecies should be subdivided into two subgroups. These subgroups correspond to HGs $5 \mathrm{~A}$ and $5 \mathrm{~B}$ and were well differentiated in our FAME study. Kämpfer and Altwegg (19) assigned 10 strains of $\mathrm{HG} 4$ to phenon 15, which is in fact quite similar to FAME cluster $B$. The clinical genospecies HG 4 is more easily separated from other members of the $A$. caviae complex on the basis of FAME data than on the basis of phenotypic data (19).

Together with FAME cluster B, FAME cluster C represents the entire $A$. caviae complex, as mentioned above. In addition, it also contains the mean fatty acid profile of two strains belonging to the genospecies $A$. veronii $\mathrm{HG} 11$. On the basis of phenotypic data (19), HGs 5A, 5B, and 6 constitute a distinct phenogroup which clusters tightly with HG 4 and exhibits very little similarity to $\mathrm{HG} 11$. So far, no correct name has been proposed for DNA homology group 11; moreover, only two strains (LMG 13075 and LMG 13076) belonging to this genospecies have been described. Strain LMG 13075 was formerly assigned to enteric group 77 (now $A$. veronii biogroup veronii $\mathrm{HG} 10$ ), but differed from this taxon genetically (it exhibited less than $70 \%$ DNA-DNA relatedness with type strain LMG 9075 of HG 10 [15]). Kämpfer and Altwegg (19) demonstrated that HG 11 is phenotypically similar to the $A$. hydrophila complex, whereas the results of a numerical analysis of FAME data indicated that this taxon exhibits a high level of similarity with the $A$. caviae complex (Fig. 1). In a recent phenotypic study Carnahan and Joseph (9) used numerical taxonomy to systematically assess 167 aeromonads, including one of the strains belonging to HG 11 (LMG 13075). In contrast to the results of Kämpfer and Altwegg (19), the simple matching dendrogram of Carnahan and Joseph (9) strongly supports the data obtained for FAME cluster $\mathrm{C}$ by placing LMG 13075 in the $A$. caviae complex. The lack of agreement between the results of the two phenotypic studies $(9,19)$ may have been caused by the different markers used for numerical analysis. Kämpfer and Altwegg (19) used 30 conventional tests, including carbon source utilization, sugar fermentation, and enzyme production tests, whereas Carnahan and Joseph (9) used a much broader spectrum of characteristics, including 50 biochemical tests and antimicrobial resistance and virulenceassociated markers.

FAME cluster D contains only $A$. veronii biogroup veronii (HG 10), which in fact belongs to a HG (HG 8/10) that also contains $A$. veronii biogroup sobria ( $\mathrm{HG} 8$ ) and cannot be distinguished from the latter by genotypic data (4). Because of the physiological diversity in this DNA group, it seemed reasonable to establish two biogroups in $A$. veronii which correspond to HGs 8 and 10. Kämpfer and Altwegg (19) confirmed this suggestion by separating the two groups into distinct phena.

FAME cluster E consists of all of the members of the $A$. hydrophila complex (HGs 1, 2, and 3 ) and $A$. sobria (HG 7). As mentioned above, HG 7 is assigned to the $A$. sobria complex but is probably misplaced because of the heterogeneity of the two strains used. Strains belonging to the $A$. hydrophila complex are usually difficult to separate phenotypically; on the other hand, they cannot be clearly classified into one phenon (19). However, Carnahan and Joseph (9) systematically placed 51 geographically and clinically diverse $A$. hydrophila strains in one group of phena by using 50 physiological tests. Moreover, DNA-DNA hybridization experiments (1) revealed a wide homology range $\left(42\right.$ to $60 \%$ at $60^{\circ} \mathrm{C}$ ) between members of the A. hydrophila complex. Our FAME data confirmed this grouping and, in addition, permitted separation of the clinically relevant taxon $\mathrm{HG} 1$ from $\mathrm{HGs} 2$ and 3 on the basis of minor quantitative variations in their fatty acid patterns.

Comparison of FAME data with data from other fatty acid studies. Only two major studies $(6,12)$ describing the fatty acid compositions of Aeromonas species have been published previously. In general, our results confirm the data in these studies. Differences in FAME data can be explained by the different culture conditions and/or different sets of strains used.

Canonica and Pisano (6) observed no qualitative differences in the fatty acid compositions of 12 Aeromonas strains that included $A$. caviae, $A$. hydrophila, and $A$. sobria strains but found some variations in the relative amounts of certain fatty acids. The ratio of $16: 0$ to $17: 0$ clearly separated the 12 aeromonads into three groups, which corresponded to the species designations. Our data revealed that the ratio of $16: 0$ to 17:0 in HGs $5 \mathrm{~A}, 5 \mathrm{~B}$, and 6 is approximately two times greater than the ratios in all of the other genospecies. However, this feature alone does not differentiate all of the taxa found in this study. Previously, Hansen and coworkers (12) made a similar statement in their study of the FAME compositions of 39 Aeromonas strains belonging to the species $A$. caviae, $A$. hydrophila, $A$. sobria, $A$. veronii, $A$. media, and $A$. schubertii. These authors found that all of their fatty acid profiles were very similar both qualitatively and quantitatively and concluded that FAME analysis is not suitable for species differentiation in the taxonomically homogeneous genus Aeromonas.

In conclusion, this is the first report of the successful use of the FAME technique for differentiating the majority of a large number of genotypically characterized Aeromonas strains. Our results were achieved mainly by using highly standardized cultivation and extraction procedures and specialized software. The differences between taxa were mainly quantitative, which suggests that differentiation of genotypically distinct HGs in the genus Aeromonas by FAME analysis is possible only when a high-resolution identification system like the MIDI system is used. We have recently begun additional fatty acid analyses of other groups of well-characterized aeromonads to determine the precise chemotaxonomic value of the FAME technique with regard to the genus Aeromonas.

\section{ACKNOWLEDGMENTS}

This research was carried out in the framework of contract G. O. A. 91/96-2 of the Ministerie van de Vlaamse Gemeenschap, Bestuur Wetenschappelijk Onderzoek (Belgium), and contract BIOT-CT910294 of the Commission of European Communities. 


\section{REFERENCES}

1. Altwegg, M. 1990. Taxonomy and epidemiology of Aeromonas spp.: the value of new typing methods. Habilitationsschrift, Universität Zürich, Zurich

2. Altwegg, M., R. Altwegg-Bissig, A. Demarta, R. Peduzzi, M. W. Reeves, and B. Swaminathan. 1988. Comparison of four typing methods for Aeromonas species. J. Diarrhoeal Dis. Res. 6:88-94.

3. Altwegg, M., M. W. Reeves, R. Altwegg-Bissig, and D. J. Brenner. 1991. Multilocus enzyme analysis of the genus Aeromonas and its use for species identification. Zentralbl. Bakteriol. 275:28-45.

4. Altwegg, M., A. G. Steigerwalt, R. Altwegg-Bissig, J. LüthyHottenstein, and D. J. Brenner. 1990. Biochemical identification of Aeromonas genospecies isolated from humans. J. Clin. Microbiol. 28:258-264.

5. Canonica, F. P., and M. A. Pisano. 1985. Identification of hydroxy acids in Aeromonas hydrophila, Aeromonas sobria, and Aeromonas caviae. J. Clin. Microbiol. 22:1061-1062.

6. Canonica, F. P., and M. A. Pisano. 1988. Gas-liquid chromatographic analysis of fatty acid methyl esters of Aeromonas hydrophila, Aeromonas sobria, and Aeromonas caviae. J. Clin. Microbiol. 26:681-685.

7. Carnahan, A. M., T. Chakraborty, G. R. Fanning, D. Verma, A. Ali, J. M. Janda, and S. W. Joseph. 1991. Aeromonas trota sp. nov., an ampicillin-susceptible species isolated from clinical specimens. J. Clin. Microbiol. 29:1206-1210.

8. Carnahan, A. M., G. R. Fanning, and S. W. Joseph. 1991. Aeromonas jandaei (formerly genospecies DNA group $9 A$. sobria), a new sucrose-negative species isolated from clinical specimens. J. Clin. Microbiol. 29:560-564.

9. Carnahan, A. M., and S. W. Joseph. 1993. Systematic assessment of geographically and clinically diverse aeromonads. Syst. Appl. Microbiol. 16:72-84.

10. Collins, M. D., A. J. Martinez-Murcia, and J. Cai. 1993. Aeromonas enteropelogenes and Aeromonas ichthiosmia are identical to Aeromonas trota and Aeromonas veronii, respectively, as revealed by small-subunit rRNA sequence analysis. Int. J. Syst. Bacteriol. 43:855-856.

11. Colwell, R. R., M. T. McDonell, and J. De Ley. 1986. Proposal to recognize the family Aeromonadaceae fam. nov. Int. J. Syst. Bacteriol. 36:473-477.

12. Hansen, W., J. Freney, M. Labbe, F. Renaud, E. Yourassowsky, and J. Fleurette. 1991. Gas-liquid chromatographic analysis of cellular fatty acid methyl esters in Aeromonas species. Zentralbl. Bakteriol. 275:1-10.

13. Havelaar, A. H., F. M. Schets, A. van Silfhout, W. H. Jansen, G. Wieten, and D. van der Kooij. 1992. Typing of Aeromonas strains from patients with diarrhoea and from drinking water. J. Appl. Bacteriol. 72:435-444.

14. Hickman-Brenner, F. W., G. R. Fanning, M. J. Arduino, D. J. Brenner, and J. J. Farmer III. 1988. Aeromonas schubertii, a new mannitol-negative species found in human clinical specimens. J. Clin. Microbiol. 26:1561-1564.

15. Hickman-Brenner, F. W., K. L. MacDonald, A. G. Steigerwalt, G. R. Fanning, D. J. Brenner, and J. J. Farmer III. 1987. Aeromonas veronii, a new ornithine decarboxylase-positive species that may cause diarrhea. J. Clin. Microbiol. 25:900-906.

16. Huys, G., R. Coopman, M. Vancanneyt, I. Kersters, W. Verstraete, K. Kersters, and P. Janssen. 1993. High resolution differentiation of aeromonads. Med. Microbiol. Lett. 2:248-255.

17. Janda, M. J. 1991. Recent advances in the study of the taxonomy, pathogenicity, and infectious syndromes associated with the genus Aeromonas. Clin. Microbiol. Rev. 4:397-410.

18. Jantzen, E., A. Sonesson, T. Tangen, and J. Eng. 1993. Hydroxyfatty acid profiles of Legionella species: diagnostic usefulness assessed by principal-component analysis. J. Clin. Microbiol. 31: 1413-1419.

19. Kämpfer, P., and M. Altwegg. 1992. Numerical classification and identification of Aeromonas genospecies. J. Appl. Bacteriol. 72: 341-351.

20. Kuijper, E. J., A. G. Steigerwalt, B. S. C. I. M. Schoenmakers,
M. F. Peeters, H. C. Zanen, and D. J. Brenner. 1989. Phenotypic characterization and DNA relatedness in human fecal isolates of Aeromonas spp. J. Clin. Microbiol. 27:132-138.

21. Lambert, M. A., F. W. Hickman-Brenner, J. J. Farmer III, and W. Moss. 1983. Differentiation of Vibrionaceae species by their cellular fatty acid composition. Int. J. Syst. Bacteriol. 33:777-792.

22. Martinez-Murcia, A. J., C. Esteve, E. Garay, and M. D. Collins. 1992. Aeromonas allosaccharophila sp. nov., a new mesophilic member of the genus Aeromonas. FEMS Microbiol Lett. 91:199206.

23. Osterhout, G. J., V. H. Shull, and J. D. Dick. 1991. Identification of clinical isolates of gram-negative nonfermentative bacteria by an automated cellular fatty acid identification system. J. Clin. Microbiol. 29:1822-1830.

24. Picard, B., and P. Goullet. 1985. Comparative electrophoretic profiles of esterases, and of glutamate, lactate and malate dehydrogenases, from Aeromonas hydrophila, A. caviae and $A$. sobria. J. Gen. Microbiol. 131:3385-3391.

25. Popoff, M. 1984. Genus III. Aeromonas Kluyver and van Niel 1936, p. 545-548. In N. R. Krieg and J. G. Holt (ed.), Bergey's manual of systematic bacteriology, vol. 1. Williams \& Wilkins, Baltimore.

26. Popoff, M. Y., C. Coynault, M. Kiredjian, and M. Lemelin. 1981. Polynucleotide sequence relatedness among motile Aeromonas species. Curr. Microbiol. 5:109-114.

27. Schubert, R. H. W., and M. Hegazi. 1988. Aeromonas eucrenophila species nova, Aeromonas caviae, a later and illegitimate synonym of Aeromonas punctata. Zentralbl. Bakteriol. Mikrobiol. Hyg. Abt. 1 Orig. Reihe A 268:34-39.

28. Schubert, R. H. W., M. Hegazi, and W. Wahlig. 1990. Aeromonas enteropelogenes species nova. Hyg. Med. 15:471-472.

29. Schubert, R. H. W., M. Hegazi, and W. Wahlig. 1990. Aeromonas ichthiosmia species nova. Hyg. Med. 15:477-479.

30. Stead, D. E. 1989. Grouping of Xanthomonas campestris pathovars of cereals and grasses by fatty acid profiling. EPPO (Eur. Mediterr. Plant Prot. Organ.) Bull. 19:57-68.

31. Stead, D. E. 1992. Grouping of plant-pathogenic and some other Pseudomonas spp. by using cellular fatty acid profiles. Int. J. Syst. Bacteriol. 42:281-295.

32. Stephenson, J. R., S. E. Millership, and S. Tabaqchali. 1987. Typing of Aeromonas species by polyacrylamide-gel electrophoresis of radiolabelled cell proteins. J. Med. Microbiol. 24:113-118.

33. Tonolla, M., A. Demarta, and R. Peduzzi. 1991. Multilocus genetic relationships between clinical and environmental Aeromonas strains. FEMS Microbiol. Lett. 81:193-200.

34. Vandamme, P., M. Gillis, M. Vancanneyt, B. Hoste, K. Kersters, and E. Falsen. 1993. Moraxella lincolnii sp. nov., isolated from the human respiratory tract, and reevaluation of the taxonomic position of Moraxella osloensis. Int. J. Syst. Bacteriol. 43:474-481.

35. Vandamme, P., M. Vancanneyt, B. Pot, L. Mels, B. Hoste, D. Dewettinck, L. Vlaes, C. Van den Borre, R. Higgins, J. Hommez, K. Kersters, J.-P. Butzler, and H. Goossens. 1992. Polyphasic taxonomic study of the emended genus Arcobacter, with Arcobacter butzleri comb. nov. and Arcobacter skirrowii sp. nov., an aerotolerant bacterium isolated from veterinary specimens. Int. J. Syst. Bacteriol. 42:344-356.

36. Vauterin, L., P. Yang, B. Hoste, M. Vancanneyt, E. L. Civerolo, J. Swings, and K. Kersters. 1991. Differentiation of Xanthomonas campestris pv. citri strains by sodium dodecyl sulfate-polyacrylamide gel electrophoresis of proteins, fatty acid analysis, and DNA-DNA hybridization. Int. J. Syst. Bacteriol. 41:535-542.

37. von Graevenitz, A., and M. Altwegg. 1991. Aeromonas and Plesiomonas, p. 396-401. In A. Balows, W. J. Hausler, Jr., K. L. Herrmann, H. D. Isenberg, and H. J. Shadomy (ed.), Manual of clinical microbiology, 5th ed. American Society for Microbiology, Washington, D.C.

38. Yang, P., L. Vauterin, M. Vancanneyt, J. Swings, and K. Kersters. 1993. Application of fatty acid methyl esters for the taxonomic analysis of the genus Xanthomonas. Syst. Appl. Microbiol. 16:4771. 